\title{
NUEVA FILOSOFÍA DE LA TÉCNICA JURÉDICA
}

Sumario: 1. Planteamiento negativo (crítica de errores) y planteamiento positivo (nuevas orientaciones) de este tema. 2. Múltiples errores en la teoría y en la práctica juridica del siglo XIx, como supuestos tomados por consabidos, aunque nunca demostrados. 3. Principales responsables de las magnas equivocaciones en el siglo XIX. 4. Programa de un análisis crítico en diferentes planos. 5. Las normas jurldicas no son proposiciones lógicas susceptibles de verdad o falsedad. 6. Los contenidos de las normas juridico-positivas no pueden ser tratados por los métodos de la lógica tradicional. 7. Crítica del deductivismo en jurisprudencia. 8. La función jurisdiccional no puede ser automática. 9. Es imposible sistematizar la jurisprudencia. 10. No hay conceptos esenciales de instituciones jurídicas históricas. 11. Las normas jurídicas individualizadas son auténticas normas jurídicas. 12. No hay diferencia entre creación y aplicación del Derecho. 19. Crítica de la separación entre cuestión de hechos y cuestión de Derecho. 14. Creación del Derecho desde abajo hacia arriba.

1. Planteamiento negativo (critica de errores) y planteamiento positivo (nuevas orientaciones) de este tema

Al presente estudio, resultado de insistentes análisis y reiteradas meditaciones a lo largo de muchos años, se le podría dar dos títulos, con signos respectivos de opuestas formulaciones: uno negativo; el otro, positivo.

El título negativo rezaría: "Diez grandes errores de la teoría y práctica jurídicas del siglo xIx." El rótulo positivo sería: "Nuevas orientaciones para la jurisprudencia en la segunda mitad del siglo xx."

En el fondo, sustancialmente, se trata de dos diferentes formulaciones verbales de un mismo tema. Porque sucede que de la crítica a fondo de las grandes equivocaciones cometidas en el siglo xix, incluso en los primeros lustros del xx, surgen las orientaciones renovadoras para un correcto desarrollo de la jurisprudencia en nuestros días.

$Y$ es curioso el hecho de que esas nuevas directrices no son, en fin de cuentas, radicalmente nuevas, sino que constituyen más bien renovaciones de posiciones añejas - contenidas en pensamientos de la Antigüedad grecoromana $\mathrm{y}$ en los anales más eminentes en la historia de la jurisprudencia. Pero, claro, no se trata de un retorno puro y simple a filosofías del pretérito, lo cual, cuando no funesto, suele casi siempre constituir algo inútil, y, a fuer de tal, estéril. Se trata de otra cosa; de un regreso en el que cargamos sobre nuestras espaldas con una serie de nuevas experiencias intelectuales, lo cual le permite a uno producir un pensamiento que pueda ser calificado como muy genuinamente del siglo xx. Una vez más, se confirma que la frase "nihil novum sub sole", tomada pura y simplemente, de manera tajante y 
a secas, constituye una gigantesca estolidez, así como, por otra parte, la expresión de un paralizante renunciamiento. Pero, en cambio, cobra en parte un sentido justificado, si a dicha frase la añadimos otra: "eadem sed aliter", es decir, tal vez "lo mismo, pero siempre de otra manera".

2. Múltiples errores en la teoria y en la práctica juridica del siglo xix, como supuestos tomados por consabidos, aunque nunca demostrados

El presente estudio se ha originado a través de un proceso de meditaciones genuinamente filosóficas: es un trabajo de filosofía. Pero es no tanto un ensayo de filosofía del Derecho, sino, más bien, de filosofía de la jurisprudencia, es decir, de la técnica jurídica, de la práctica de las profesiones jurídicas. Sin embargo, tal vez, es más seguramente, ése sea un importantísimo tema de una genuina Filosofía del Derecho; porque, al fin y a la postre, el Derecho es un instrumento de índole esencialmente práctica, un artefacto para producir determinados efectos en la vida social, precisamente los efectos que constituyen la realización de unos propósitos humanos justificados y aun imprescindibles. Cierto que está lejísimos de mi ánimo cualquier actitud de menor aprecio para la filosoffa jurídica acentuadamente teorética, académica, a la que he conșagrado la mayoría de los años de mi vida, y que sigo cultivando con invariable devoción. Sucede, empero, que, cuanto más se ahonda en los temas puramente teóricos de filosofía del Derecho, se comprende, cada vez con mayor claridad, que ésta debe prestar atención a las cuestiones de la práctica jurídica: no sólo una atención marginal o complementaria, antes bien, una atención central.

$\mathrm{Y}$, así, acontece que, cuando se procede a un riguroso examen crítico de la conciencia juridica, no sólo al nivel teórico, sino también en el plano de la práctica, y haciendo gran hincapié sobre esta segunda, avizoramos auras de renovación, tanto para el pensamiento teorético, como para la revitalización de los menesteres jurídicos en la práctica. $O$, diciendo lo mismo con otras palabras: la reflexión crítica sobre los temas técnicos produce una mayor limpieza intelectual para el tratamiento de las cuestiones puramente teoréticas; y, al mismo tiempo, abre también las vías para una mayor justicia práctica y para una más satisfactoria eficacia de ésta.

\section{Principales responsables de las magnas equivocaciones en el siglo xix}

Cuando me he referido a diez grandes errores de la teoría y prácticas jurídicas del siglo XIX, no apuntaba especialmente contra una determinada doctrina, o contra un cierto autor. No se trata de eso. Principalmente se trata de otra cosa: de emanciparnos de equivocaciones comunes a casi todas 
las filosofías jurídicas del siglo xIx, equivocaciones proyectadas con resultados funestos en la práctica, pues produjeron monstruosas injusticias.

Principalmente se trata de una serie de supuestos que casi todos los juristas teóricos y prácticos del siglo xIX tomaron como algo consabido, sin discutirlos, sin intentar fundamentarlos, sin incorporarlos a un cuerpo de teoria. Todas esas equivocaciones constituyen un repertorio de denominadores comunes de casi todas las manifestaciones de la teoría y la práctica jurídicas del siglo $\mathrm{xIx}$, incluso de los primeros lustros del $\mathbf{x x}$.

Los responsables de esos grandes errores fueron muchos factores, y de variada índole. Pero, principalmente, la invasión del campo jurídico por el espíritu cartesiano, es decir, por el espíritu matemático-geométrico, por el afán de exactitud. Adviértase que en esa acusación contra tal espíritu, no va aneja, de ninguna manera, una menor estima a la obra genial del fundador de la filosofía moderna. Es algo diferente: se combate el indebido trasplante de una especie de imperialismo matemático al ámbito de los problemas humanos prácticos, y, entre éstos, al de los jurídicos. La influencia de este tipo de espíritu, que apunta a la exactitud y al deductivismo de índóle matemática, hizo suponer, gratuita e infundadamente, que los problemas jurídicos pueden ser despachados mediante métodos de lógica tradicional. Ahora bien, no se trat $\delta$ de aportar una justificación suficiente de tal propósito. Lo que aconteció es que eso se vio como algo consabido de antemano, sin previa reflexión, y sin título justificativo de ninguna especie.

Ahora bien, a pesar de que cabe referirnos a esas grandes equivocaciones como denominadores comunes que constituyeron los efectos de la indebida invasión del espíritu matemático en el campo de la jurisprudencia, sin embargo, es posible señalar, de modo especial, la influencia directa de algunos factores muy característicos, de algunos "villanos", por emplear una locución popular usada en el lenguaje de la novelística y del cine.

Tales factores específicos, o tales "villanos", fueron: la Escuela Francesa de la Exégesis; ${ }^{1}$ los pandectistas alemanes; y la llamada jurisprudencia conceptualista. ${ }^{2}$ También, las enseñanzas del profesor Beale de la Universidad de Harvard, quien se convirtió a fines del siglo xix en el Máximo Pontífice del Common Law: ${ }^{3}$

Así mismo debe señalarse que en los mayúsculos errores, a los que he aludido ya y que criticaré en detalle, corresponde una dosis de responsabilidad a algunos extravíos del formalismo neokantiano, sacado de quicio.

1 Cfr. J. Bonnecase, La Escuela de la Exégesis en Derecho Civil, trad. por José Cajiga, Puebla, México.

2 La Jurisprudencia Conceptualista estuvo representada en Alemania, y también en otros paises, por muchos autores, pero su exponente principal fue el famoso pandectista Windscheid (Lehrbuch des Pandektenrechts, 5. Auflage). También: Böcking, Pandekten; Kierulff, Theorie des gemeinen Civilrechts; etc.

3 Cfr. Beale, Treatise on the Conflicts of Laws. 
Y no se debe omitir en esa especie de acta de acusación resumida, los estragos producidos por la persistencia del positivismo jurídico, en sus varias formas: positivismo sociológico francés; positivismo lógico de raíz neokantiana; y realista psicológico (de la escuela escandinava).

\section{Programa de un análisis critico en diferentes planos}

Tangencial y episódicamente, haré, en este estudio, algunas referencias críticas a varias doctrinas de filosofia del Derecho. Pero repito que el presente trabajo no es predominantemente una monografía filosófico-jurídica, antes bien un ensayo de filosofía de la jurisprudencia, con el propósito de sacar de modo directo inmediatas enseñanzas para el ejercicio correcto de las profesiones prácticas del Derecho.

Lo que intento es presentar un rigoroso análisis crítico de lo que aconteció en la jurisprudencia, poco más o menos, desde el tercer decenio del siglo xIx hasta el segundo del siglo xx. En tal análisis, tomaré en cuenta los problemas de la ciencia técnico-dogmática del Derecho; las cuestiones que se plantean en el proceso jurisdiccional de la individualización de las normas; támbién, las actitudes que deben ser correctas para el legislador; y el modo de operar que éste debe desenvolver.

Hablaré de varios errores mayúsculos, garrafales, funestos: nada menos que de diez tremendos dislates. Pero, tal vez, en el fondo, no se trate de diez errores, cada uno de ellos independiente de los demás, sino más bien de varios aspectos y diversas derivaciones o proyecciones de una misma equivocación básica: la primera, de la cual paso a ocuparme inmediatamente.

\section{Las normas juridicas no son proposiciones lógicas susceptibles de verdad o falsedad}

Seguramente el error de mayor tamaño, descomunal en lo teórico y funesto en la práctica, y, a la vez, la fuente principal de los otros desvaríos, sea el siguiente: el haber creído - sin haber aportado ninguna razón justificadora- que los contenidos de las normas del Derecho son proposiciones lógicas, sobre las cuales cabe un juicio de verdad o de falsedad. Aunque parezca mentira, pero no lo es, este error arraigó tanto, que todavía en el presente tropieza uno a veces con estudiantes atolondrados que dicen: "el Derecho es una ciencia..."

¡No, las normas jurídico-positivas no pueden ser verdaderas ni falsas! ¡No, el Derecho no es una ciencia!

Las normas del Derecho positivo no son enunciados de ideas con intrínseca validez; ni son tampoco descripciones de hechos; ni son expresión de 
ningún ser. Por el contrario, las normas del Derecho positivo son instrumentos prácticos, elaborados y construidos por los hombres, para que mediante su manejo produzcan en la realidad social unos ciertos efectos, precisamente el cumplimiento de los propósitos concebidos. ${ }^{4}$

El Derecho no es una ciencia, sino que es eso que acabo de expresar, un trebejo para provocar en la realidad social unos ciertos resultados. Claro que, sin duda, hay una ciencia del Derecho, a saber la ciencia que estudia ese instrumento práctico que el Derecho es. $\mathrm{Y}$ asimismo hay una filosofía del Derecho. Pero nunca se debe confundir la ciencia y filosofía del Derecho, con el Derecho que es objeto de esos dos tipos de estudio.

Decir que el Derecho es una ciencia sería un desatino tan grande como si en una cátedra de zoología se afirmase que el elefante o la cucaracha es una ciencia. La ciencia no está ni en el elefante ni en la cucaracha, sino en la zoología, estudio científico de esos y de todos los demás animales.

El Derecho como realidad es un arte práctico, una técnica, una forma de control social. De ese utensilio, que el Derecho es, no se puede predicar ni el atributo de verdad ni el de falsedad, porque el Derecho no es un ensayo de conocimientos, ni vulgares ni cientificos. Claro que el Derecho puede y debe ser enjuiciado desde los ángulos de otros valores, por ejemplo, desde los puntos de vista de: justicia, dignidad de la persona individual, libertades básicas, conveniencia, oportunidad, servicio al bienestar general, viabilidad, eficacia, prevención de mayores males, etc.; en suma, desde el punto de vista de la justicia y de los demás valores por ésta implicados, así como también desde el punto de vista de otros valores, que suelen englobarse bajo la denominación de prudencia.

\section{Los contenidos de las normas juridico-positivas no pueden ser tratados} por los métodos de la lógica tradicional

El segundo gran error, o más bien dicho la inmediata derivación del primero de los desatinos del que acabo de ocuparme, consiste en querer tratar el Derecho empleando los métodos de la lógica tradicional, es decir, de

4 Cfr. Luis Recaséns Siches, Nueva Filosofia de la Interpretación del Derecho, Publicaciones de "Diánoia", Fondo de Cultura Económica, México, 1956, pp. 31-177; Unicidad en el Método de Interpretación del Derecho, en el Volumen Homenaje ofrecido al Profesor Luis Legaz Lacambra en ocasión de sus bodas de plata con la cátedra, Universidad de Santiago de Compostela, 1960; "Interpretación del Derecho", artículo en la Enciclopedia Juridica Omeba, Buenos Aires, 1961; "Rivolozione Teorica e Prattica nell'Interpretazione del Diritto", en Rivista Internazionale de Filosofia del Diritto; "The Logic of the Reasonable as Differentiated from the Logic of the Rational (Human Reason in the Making and Interpretation of the Law)" en Essays in Jurisprudence in Honor of Roscoe Pound, Bobbs-Merrill, Indianapolis, 1962; "The Material Logic of the Law; A New Philosophy of Juridical Interpretation" en Archiv für Rechts und Sozialphilosophie, Neue Folge, 4, Vol. 1965 . 
la lógica habitualmente llamada matemático-física, deductiva, sistemática, de la lógica que va desde su fundación en el Organon de Aristóteles hasta las lógicas simbólicas contemporáneas. Esa lógica vale para la matemática, la física y otras ciencias de la naturaleza; pero es inservible para el tratamiento de los problemas prácticos de conducta humana - domésticos, familiares, económicos, sociales, jurídicos, etc. Cuando en los asuntos prácticos de la humana existencia se quiere desatinadamente emplear la lógica de lo "racional", ésta, si es que no produce desquiciamientos teóricos y catástrofes prácticas, se muestra como inservible.

Ahora bien, que nadie se asuste ni escandalice, interpretando torcidamente lo que acabo de decir, como un propósito de dejar librada la jurisprudencia a un vitalismo irracional, irresponsable, a la irrupción de la arbitrariedad, al imperio del capricho, al reino de la corazonada injustificable, etc. No se trata de eso. De ninguna manera. En el campo de la jurisprudencia, al igual que en el de los problemas sociales, económicos y políticos, se efectúa el desahucio sólo contra la lógica de "lo racional", contra la lógica pura, contra la lógica físico-matemática. Ahora bien, esa lógica tradicional no es la totalidad de la lógica, antes bien tan sólo una provincia particular del logos, al lado de otras zonas de éste, de otras regiones del logos, las cuales son tan "lógica" como la de lo racional, pero diferentes de ésta. Aquí no me propongo intentar el diseño de un mapa total del logos, sino solamente llamar de modo enfático la atención hacia otra provincia de éste, a saber: hacia el logos de los asuntos humanos o "lógica de lo razonable". Como quiera que he publicado sobre este tema múltiples obras en varios idiomas, no voy aquí a repetir lo que he desenvuelto en esas otras páginas mías. Solamente, con concisión telegráfica, recordaré los siguientes puntos:

A) La lógica de lo razonable es lógica, tan lógica como la de lo racional; o incluso cabría decir más lógica que ésta, pues tiene una finalidad de "comprensión" de la cual carece la lógica pura tradicional.

$B$ ) El logos de lo razonable posee una dimensión intensiva (consejo, norma, imperativo, fuerza creadora) desconocida por la lógica tradicional, esto es, por la lógica de la ciencia matemática y de las ciencias de la naturaleza.

C) La lógica de lo razonable se encuentra transida por juicios de valor, por estimaciones.

D) La lógica de lo razonable, contiene conexiones entre valores y fines; entre fines y medios, y respecto de éstos requiere congruencia, corrección ética, y eficacia.

E) La lógica de lo razonable está rigorosa y estrictamente fundada; pero sus expresiones no tienen ni pueden tener una exactitud de tipo matemático. En las valoraciones compendiadas bajo el nombre de prudencia, se da la posibilidad de gradaciones, de un más y de un menos. 
F) La lógica de lo razonable refleja las enseñanzas de la experiencia práctica, es decir, de la razón vital (las propias experiencias individuales) y de la razón histórica (los aleccionamientos sociales de las experiencias del prójimo).

Dentro de este segundo error, del que me estoy ocupando ahora, figura otro enorme dislate: la aspiración de elaborar "conceptos esenciales", "nociones puras", "ideas a priori" de las instituciones y normas jurídicas históricas, por ejemplo: la hipoteca, la cuenta corriente bancaria, el senado, el impuesto sobre la renta, etc. Esas instituciones jurídicas históricas no tienen una "esencia"; como tampoco tiene una "esencia" el modelo 200 de automóvil Ford. Con respecto a esas instituciones lo único que se puede hacer es observar la estructura y el funcionamiento que les dio el legislador, y describir esa estructura y ese funcionamiento. Lo mismo, que ante el mencionado modelo de automóvil, o cualquier otro. Basta con describirlo.

\section{Critica del deductivismo en jurisprudencia}

El segundo de los grandes errores, que acabo de comentar engendró otra magna equivocación: la frenética manía de un deductivismo ilimitado en el campo de la jurisprudencia. Tal cosa constituyó el efecto de haber supuesto gratuitamente que las normas del Derecho positivo son enunciados ideales y de que el método propio de tratarlos es el de la lógica tradicional. Entonces comenzó el delirio de la inferencia, la exaltación del silogismo. Esto trajo consigo uno de los más grandes disparates que se hayan producido en la teoría jurídica: aquella pintoresca doctrina de que la sentencia judicial es un silogismo, cuya premisa mayor sería la norma jurídica pertinente; cuya premisa menor estaría representada por la enunciación de los hechos probados y jurídicamente calificados; y cuya conclusión consistiría en el fallo. Puede calificarse esa doctrina como muy simple, en dos acepciones de este vocablo: primero, porque no es complicada; y, segundo, simple, en el sentido de boba o necia. No olvido, naturalmente, que esa tontería fue expuesta y sostenida por muy eminentes juristas. Al aplicar a tal teoria los calificativos que he usado, no trato ni remotamente de ofender a los muchos ilustres autores que de ella se hicieron eco, y cuya obra, por lo demás y con la excepción de este punto, es muy respetable y en gran parte digna de aplauso. Bien sabido es, pues de ello tenemos abundante experiencia, el hecho de que excelentes autores alguna vez caen en una botaratada, sea por inadvertencia, sea por haber seguido inertemente algo que estaba en boga. Nada hay, por lo tanto, en mis palabras, que empañe la justa gloria de muchos de los insignes autores que incurrieron en ese disparate de haber concebido la sentencia judicial como un silogismo. Esta aberración fue sostenida y enseñada durante un siglo aproximadamente. 
Claro que, hoy en día, ya nadie comulga con ese desbarro.

La concepción de la sentencia como un silogismo fue atacada ya a fines del siglo xIX por Ihering, ${ }^{5}$ Holmes, ${ }^{6}$ Gény ${ }^{7}$ y otros; y durante los cinco primeros lustros del siglo $\mathrm{xx}$, por Ehrlich, ${ }^{8}$ Kantorowicz, ${ }^{9}$ Cruet, ${ }^{10}$ Morin, ${ }^{11}$ Pound, ${ }^{12}$ Cardozo, ${ }^{13}$ Kelsen ${ }^{14}$ y muchos más y muy egregios iusfilósofos. Todos esos eminentes iusfilósofos produjeron, cada vez con mayor y más eficaz violencia, un ataque contra esa estólida concepción de la sentencia como un silogismo, a lo que podríamos llamar un primer nivel. Pero más tarde surgieron nuevas críticas en un plano mucho más profundo, y desde luego definitivamente destructor de aquel extravío mental.

Pero veamos, ante todo, cuál fue el primer nivel de ataque. En resumen, podríamos extraer de todas las severas críticas contra aquella doctrina el siguiente denominador común: ¿Qué quieren ustedes, quieren seguir sosteniendo tozudamente aquel error de que la sentencia es un silogismo? Bueno, pueden continuar haciéndolo, si gustan. Pero, en todo caso, habrán de reconocer ustedes que el meollo de la función judicial y las graves respon-

5 Cfr. Rudolf von Ihering, Scherz und Ernst in Jurisprudenz, 1884.

6 Cfr. Oliver Wendell Holmes, The Path of the Law, 1897; Law in Science and Science in Law, 18gg; The Common Law: Collected Legal Papers, 1920; The Holmes Reader, Selected and Edited by Julius J. Marke, Oceana, New York, 1955.

7 Cfr. François Gény, Méthode d'Interpretation et Sources en Droit Privé Positif, 1899, 2ème éd., 1919; Science et Technique en Droit Privé Positif: Nouvelle Contribution à la Critique de la Méthode Juridique, 2ème éd., 1922; Ultima Verba, 1951.

8 Cfr. Eugen Ehrlich, Freie Rechtsfindung und freie Rechtswissenschaft, 19o3; Sozio. logie und Jurisprudenz, 1903.

- Cfr. Hermann Kantorowicz (bajo el pseudónimo de Gnaeus Flavius), Der Kampf um die Rechtswissenschaft, 1906; y con su propio nombre: Recht und Wahrheit in unserer heutigen Justiz, Igo8; "Rechtswissenschaft und Soziologie", en Verhandlungen des ersten deutschen Soziologentages, 1911; Aus der Vorgeschichte der Freierechtslehre, Mannheim, 1925; "Some Rationalism about Realism", en Yale Law Journal, 1934; "Savigny and the Historical Law School", en Law Quarterly Review, 1937; La Definición del Derecho, trad. J. M. de la Vega, Revista de Occidente, Madrid, 1964.

10 Cfr. Jean Cruet, La Vie du Droit et l'Impuissance des Lois, Paris, 1908.

11 Cfr. Gaston Morin, La Revolte des Faits contre le Code, Paris, 1920; La Loi et le Contrat, Paris, 1927; La Revolte du Droit contre le Code, 1935.

12 La última versión del pensamiento filosófico-jurídico de Roscoe Pound la dio éste en su monumental obra (en cinco volúmenes) Jurisprudence, West Publishing Company, St. Paul, Minn., 1959.

13 Cfr. Benjamin Cardozo, The Nature of the Judicial Process, Yale University Press, 1921; The Growth of the Law, Yale University Press, 1924; The Paradoxes of the Legal Science, Columbia University. Press, New York, 1928; Selected Writings of Benjamin Cardozo, 1947.

14 Cfr. Hans Kelsen, Hauptprobleme der Staatsrechtslehre, entwickelt aus der Lehre vom Rechtssatzes, 1911; Allgemeine Staatstehre, Springer, Berlin, 1925; Compendio de una Teoria General del Estado, con un Estudio Preliminar sobre la Teoria Pura del Derecho $y$ del Estado por Luis Recaséns Siches, $2^{\text {a }}$ ed. Editorial Bosch, Barcelona, 1934; General Theory of Law and State, Twentieth Century Legal Philosophy Series, Harvard University Press, 1945; Reine Rechtslehre; mit einem Anhang: das Problem der Gerechtigkeit, neue bearbeitete und erweiterte Auflage, Deuticke, Wien, 1960. 
sabilidades que ésta entraña no radican en la sencilla operación de sacar una conclusión de dos premisas, para completar un supuesto silogismo. Sentadas la premisa mayor y la premisa menor, la operación de extraer la consecuencia puede realizarla correctamente un niño de 10 años o incluso las sirvientas analfabetas. En todo caso, tiene uno que darse cuenta de que la auténtica miga de la función judicial y la pesada carga de la misma no consistirían jamás en deducir la conclusión de dos premisas, sino en la tarea, muchas veces dificilísima, de sentar las dos premisas correctas.

Los jueces y los abogados tienen abundante experiencia del hecho de que muchas veces se encuentran con respecto a un litigio o proceso, con dos o más normas del Derecho vigente, cada una de las cuales aparentemente podría parecer la pertinente para decidir la controversia planteada; con dos o más normas de igual rango formal y de la misma fecha. Las más de las veces esas dos o más normas suelen ser diferentes artículos de una misma ley o de un mismo código. Entonces, el juzgador tiene que elegir entre esas varias normas. Ahora bien, para tal faena de elección, la lógica formal no le presta ninguna ayuda; ninguna, en absoluto. $\mathrm{Y}$ esto lo reconocen con ejemplar sinceridad los más eminentes cultivadores de la lógica formal de lo jurídico, es decir de la lógica de las formas a priori del Derecho. Tal escogimiento puede efectuarse única y exclusivamente por virtud de una valoración de contenido; valoración de contenido a la cual es por entero y en absoluto ajena la lógica formal. Éste no es un problema de lógica formal del Derecho, antes bien, una cuestión de lógica material, de lógica de los contenidos, en suma no de lógica de "lo racional" sino, por el contrario, de lógica de "lo razonable". Baste con lo dicho, por lo que se refiere a la supuesta premisa mayor.

Según aquella desatinada concepción de la sentencia como un silogismo, la premisa menor de éste se hallaría representada por la enunciación de los hechos probados y jurídicamente calificados. Esto puede sonar como algo muy sencillo, incluso con apariencia de algo bonito; pero, por debajo de esas palabras pululan, con dramáticas dificultades, muchísimos problemas que atosigan la mente del juzgador.

Por de pronto, recordemos que el Derecho no opera jamás con realidades plenarias, con hechos desnudos, antes bien, únicamente con las dimensiones reales que sean relevantes desde el punto de vista jurídico establecido. por las normas. Del conjunto total de hechos reales en los que se origina una situación jurídica, conflictiva o no conflictiva, el Derecho filtra tan sólo algunos de ellos, y de éstos extrae únicamente las porciones relevantes desde el ángulo jurídico, haciendo a un lado todos los demás componentes.

Ahora bien, adviértase que para esa tarea de filtrado de los hechos, con el propósito de atender tan sólo a sus ingredientes y a sus dimensiones jurídicamente relevantes, el juez o el abogado no operan entonces de modo ex- 
clusivo con hechos, sino que miran las realidades a través de las antiparras de las normas de Derecho. O sea: el jurista nunca maneja hechos puros y simples, nudas realidades, antes bien, un compuesto integrado por componentes fácticos y enfoques normativos. Esta observación basta para destruir definitivamente la hipótesis de que en la sentencia hay una premisa menor, representada exclusivamente por la expresión de unos hechos.

Pero los hechos, cuya consideración interviene en la sentencia, además de discriminados desde el punto de vista jurídico, deben quedar suficientemente probados.

Nótese, ante todo, en este punto, que cabe formular la pregunta de qué haya de ser lo primero, y qué deba ser lo segundo: si primero la prueba de los hechos y después su calificación jurídica, o, a la inversa, primero la calificación y luego la prueba. Pero esta pregunta, planteada en tales términos, no es posible contestarla satisfactoriamente. Pues, ¿cómo se va a ocupar el juzgador de la calificación de unos hechos que aún no estima probados?; y, viceversa, ¿̇cómo va a preocuparse el juzgador de la prueba de unos hechos, antes de haber discriminado o extraído de la realidad aquellos componentes que tengan relevancia para el Derecho? Lo que sucede es que aquí se trata de una función mental compleja, en la que se encuentran íntima e inseparablemente entrelazadas dimensiones fácticas y dimensiones normativas, formando una especie de textura orgánica inescindible.

Pero hay más todavía sobre ese punto de la segunda (supuesta) premisa. La prueba de los hechos no puede jamás expresarse como un simple enunciado. Por el contrario, es siempre y necesariamente una valoración, un juicio estimativo. El juez debe apreciar en cada caso concreto el valor de persuasión de los medios de prueba empleados por las partes. El juez debe apreciar si un documento aparentemente público puede ser en efecto considerado como tal, o si, por el contrario, en razón de faltarle algún requisito esencial, carece de esa categoría de "público". El juez debe valorar la credibilidad de los documentos privados. El juez debe apreciar en qué medida y hasta qué punto debe o no tomar en consideración dictámenes periciales. El juez debe valorar la prueba testifical. Ahora bien, la prueba testifical, la cual es imprescindible en gran número de procesos, constituye algo superlativamente frágil, que debe ser tratado con superlativa cautela, con mucha perspicacia, con no poca precaución, desenvolviendo una difícil labor de aquilatamiento. No se trata tan sólo, ni eso es lo más difícil, de juzgar sobre la :credibilidad de algún testigo. Un juez medianamente talentoso descubre al instante al testigo mendaz. El grave problema lo plantean los testigos honestos, de buena fe, pero con exceso de imaginación - la mayoría suele poseer una abundancia de fantasía - quienes honestamente creen que en sus deposiciones relatan lo que efectivamente vieron y oyeron; pero que, en realidad, lo que ofrecen es una reconstrucción o reconfiguración de una parte de 
lo que vieron y oyeron, mezclado con las aportaciones de su propia imaginación. $Y$ al juez compete apreciar con agudeza, con fundamento, con perspicacia, con sagacidad, con prudencia, con claro discernimiento, aquello que en el testimonio de los testigos constituye un factor probatorio, y desdeñar lo que representa tan sólo una deformación por la fantasía.

Pero a todo eso añádase que, como certeramente observan los realistas norteamericanos, el juzgador es, a su vez, un testigo del testimonio prestado por los testigos. Y, en tanto que tal, el juez puede también ser víctima de análogos defectos en los que incurren los testigos. Para evitar esto, el juez tiene que esforzarse en ser sutil, penetrante, casi clarividente, podríamos decir.

El segundo nivel, mucho más profundo, de ataque contra la aberrada definición de la sentencia como un silogismo, va mucho más lejos. Los autores que han producido ese segundo ataque, en un plano mucho más radical y ya definitivamente destructor, sostienen que la sentencia no es ni remotamente un silogismo: no lo es ni desde el punto de vista psicológico; ni lo es tampoco en absoluto como un complejo de ideas.

En esta segunda ofensiva mucho más radical y destructora, figuran los representantes del movimiento jurídico realista norteamericano (principalmente, Llewellyn ${ }^{15}$ y Frank $^{16}$ ). Hace aproximadamente ya unos $4^{0}$ años se llevó a cabo una encuesta de alcance mundial entre jueces de todos los niveles, preguntándoles que expusieran el modo como funcionaba su mente al administrar justicia. Aunque parezca asombroso, las contestaciones en su inmensa mayoría resultaron no sólo concordes, sino incluso muy parecidas. Los más declararon que muchísimas veces al enfrentarse con un proceso, por de pronto, se sentían en las tinieblas, sumidos en un mar de confusiones, indecisos, sin acertar a ver de modo claro el nudo de la controversia. Procedian entonces a contemplar el asunto por arriba, por abajo, por todos sus lados, ponderando todos sus componentes, valorando todas sus dimensiones, intentando calibrar el alcance de todos sus factores, estimando la significación de los problemas implicados. En suma, estrujando o rumiando mentalmente el litigio. A veces, acontecía que el estado de confusión, de titubeo, de oscuridad, persistía durante horas, o dias, en ocasiones incluso durante semanas. Pero llegaba un momento en que, súbitamente, se hacía plena claridad en la conciencia del juez: entonces, el juzgador sabía perfectamente

15 Cfr. Karl Llewellyn, Jurisprudence, Realism in Theory and Practice, University of Chicago Press, 1960.

16 Cfr. Jerome Frank, Law and the Modern Mind, 6th edition, Coward-McCann, New York, 1949; Courts on Trial, Myth and Reality in American Justice, 1950; "Palabras y Música: Algunas Aberraciones en Ia Interpretación de las Leyes", en el volumen El Actual Pensamiento Juridico Norteamericano, Editorial Losada, Buenos Aires, 1951; Fate and Freedom: A Philosophy for Free Americans, Revised edition, Beacon, Boston, 1953; La Influencia del Derecho Europeo Continental en el Common Law, Editorial Bosch, Barcelona, 1957 . 
cómo debía sentenciar. Lo que pasaba en ese instante de súbita iluminación de la conciencia era una especie de aparición en esbozo del fallo. Ahora bien, en ese boceto de fallo se contenía no sólo la decisión, sino también los hechos probados y jurídicamente calificados, a la vez que la consideración de los mismos a la luz de la norma jurídica pertinente. Es decir, lo que acaecía no era un proceso mental que empezase con la constatación de la norma pertinente, que fuese seguido después por la enunciación de los hechos probados y jurídicamente calificados; y que terminase como conclusión, con el fallo. No había nada de un tal proceso psíquico progresivo, que avanzase a través de esas tres etapas. Por el contrario, primero no había nada; después, súbitamente, lo había todo: el fallo integrado por tres dimensiones inseparables, a saber, la decision, los hechos probados y jurídicamente calificados, y la norma. Pero esas tres dimensiones, recíprocamente entrelazadas de manera inescindible, forman una totalidad, cuyas partes son inseparables, cada una de ellas de las otras dos. O, expresando lo mismo con otras palabras, mediante una metáfora: primero no había nada; después, súbitamente, aparecía un triángulo; pero un triángulo ya constituido como tal, y no habiéndose formado por la adición sucesiva de sus tres lados. Por el contrario, habiéndose presentado ya como triángulo constituido, cuyos componentes son mutuamente indivisibles, inseparables.

El realista norteamericano Jerome Frank denominó este acto mental "hunch", corazonada, premonición, presentimiento, latido. Pero con este vocablo puso en peligro la solidez y la corrección de su crítica contra la sentencia como un silogismo, y la presentación de ésta como un acto mental unitario e indivisible.

En realidad, se trata de una clara intuición intelectiva, en la que no hay componentes fortuitos, en la que no hay factores de azar, en la que no interviene ningún impulso ajeno a la razón.

En verdad, no se trata de ningún descubrimiento de algo nuevo, que no fuese antes conocido. La llamada psicología de las formas o estructuras o configuraciones (Gestaltspsychologie) desenvuelta a través de las investigaciones de Koffka, Wertheimer y Köhler, ${ }^{17}$ aportó una destructora crítica del asociacionismo atomista; y puso en evidencia la realidad de actos mentales complejísimos pero unitarios, en los que se ilumina súbitamente una situación complicada; y esto, mediante una especie de intuición de una totalidad.

Lo dicho vale en lo que atañe a la realidad psicológica de la función judicial. Pero sucede que, además de la psicología de las formas o estruc-

17 Cfr. K. Koffka, "Psychologie" en la obra publicada por Max Dessoir, Lehrbuch der Philosophie, tomo II; M. Wertheimer, Drei Abhandlungen zur Gestalttheorie, 1924; Wolfgang Köhler, Gestalt-Probleme und Anfänge einer Gestaltheorie, 1922. 
turas, con anterioridad hubo filósofos que descubrieron estructuras ideales muy complejas pero también unitarias, orgánicas, cuyos ingredientes no están por así decirlo asociados, antes bien trabados recíprocamente de modo esencial, formando totalidades. Esto fue atisbado primero en algunas investigaciones de Meinong ${ }^{18}$ y Ehrenfels. ${ }^{19}$ Pero esa noción de estructura fue desarrollada plenamente sobre todo por Husserl, ${ }^{20}$ y también por Dilthey, ${ }^{21}$ quienes descubrieron la llamada conexión de sentido, que se da no sólo en procesos psíquicos subjetivos, sino también objetivamente en los productos de la cultura.

Así pues, con sólida base en la psicología de las formas y además en la teoría filosófica de los complejos ideales objetivos, hoy podemos negar terminantemente que la sentencia judicial sea un silogismo; y podemos, a la vez, afirmar decisivamente: primero, que, psicológicamente, la sentencia judicial es una intuición intelectiva de una estructura total compleja, cuyos componentes son inseparables; $y$, segundo, que objetivamente constituye un complejo ideal orgánico, cuyos ingredientes se hallan trabajados entre sí de modo recíproco e inescindible.

\section{La función jurisdiccional no puede ser automática}

El cuarto error, en fin de cuentas, es la proyección o consecuencia práctica del tercer dislate que acabo de examinar, de la manía deductivista o silogistica en el campo de la jurisprudencia. Ese cuarto error consiste en haber concebido la función judicial, y sobre todo la meta ideal de ésta, como un proceso automático. Se estimaba que el juez mejor sería aquel que no fuese inteligente, antes bien, que actuara como una especie de mecanismo automático: algo así como un aparato con tres ranuras y un botón o una manivela. Supuestamente, dentro de la primera ranura se introducirían los preceptos legales pertinentes; en la segunda se metería la constatación de los hechos ya jurídicamente calificados; y, después, apretando el botón o

18 Cfr. Alexius von Meinong, Psychologische-ethische Untersuchungen zur Wertheorie, 1894; Uber Gegenstände höherer Ordnung auf deren Verhältnis zur inneren Wahrnehmung, 1896; Untersuchungen zur Gegenstandstheorie und Psychologie, 1904; Uber die Stellung der Gegenstandstheorie im System der Wissenschaften, 1907; Zur Erkenntnistheorie und Gegenstandstheorie, 1913.

19 Cfr. Christian von Ehrenfels, Uber Gestaltsqualitäten, 18go; Grundbegriffe der Ethik, 1907 .

20 Cfr. Edmund Husserl, Logische Untersuchungen, 19oo; Ideen zu einer reinen Phänomenologie und phänomenologischen Philosophie, 1913; Formale und Transzendentale Logik, 1929; Nachwort zu meinen Ideen, 1929; Méditations Cartesiennes: Introduction à la Phénomenologie, 1991; Erfahrung und Urteil, Untersuchungen zur Genealogie der Logik, 1939.

21 Cfr. Wilhelm Dilthey, Einleitung in die Geisteswissenschaften, 1883; Ideen zu einerbeschreibende und zerliegende Psychologie, 1894; Die Entstehung der Hermeneutik, 1900; Der Aufbau der geschichtlichen Welt in der Geisteswissenchaften, 1910. 
haciendo girar la manivela, saldría por la tercera ranura el fallo ya redactado, esto es, la decisión.

Claro es que este colosal desvario, en cuanto a su surgimiento, se explica por una preocupación política que imperó en el siglo xvirI: la desconfianza hacia los funcionarios, incluso hacia los judiciales (aunque éstos fuesen vistos con mejores ojos que los administrativos); y la plena confianza en la objetividad impersonal de la ley. Esas actitudes, que rigieron en el siglo xviII, fueron factores muy importantes en las grandes revoluciones de Occidente y en los movimientos constitucionalistas. A tanto llegó esta preocupación, que el legislador revolucionario francés, al instituir la Corte de Casación, no la estableció como un tribunal, sino como un comité apendicular del poder legislativo.

Pero desde entonces hasta acá ha llovido mucho, hemos acumulado ingentes volúmenes de experiencia, de análisis científicos y de exámenes filosóficos, que han mostrado que es evidente que el juez siempre crea Derecho, quiéralo o no, necesaria e inevitablemente. Porque las leyes, en sí mismas y por sí solas, no pueden ser cumplidas ni impuestas. Para ser cumplidas o para ser impuestas necesitan ineludiblemente de un proceso de individualización, sea de individualización espontánea por los sujetos obligados a cumplirlas, sea por medio de una individualización autoritaria a través de los actos jurisdiccionales (sentencias judiciales y resoluciones administrativas). Es asi, porque las leyes, en tanto que normas generales, emplean el único lenguaje que pueden usar: el lenguaje genérico y abstracto. En cambio, la realidad humana que debe ser configurada por las leyes es siempre particular y concreta.

La afirmación de que inevitable y forzosamente el juez crea siempre Derecho no significa ningún propósito de montar al juzgador por encima de la ley. Significa tan sólo que el juez es un componente esencial e imprescindible del orden jurídico positivo. Tanto, que hay órdenes jurídicos, como los primitivos, sin legislador; pero no puede haberlos sin órganos jurisdiccionales.

Por otra parte, es certera la observación hecha por Frank: ¿qué prefieren ustedes, jueces estúpidos, que es lo que sería un aparato automático, o, por el contrario, jueces talentosos, inteligentes y honestos?

\section{Es imposible sistematizar la jurisprudencia}

En el presente, cada día se extiende hoy más y más el firmísimo convencimiento de que es de todo punto imposible la sistematización de la ciencia dogmático-técnica del Derecho. Esta afirmación la sostienen no sólo muchos iusfilósofos, sino también los más destacados renovadores contemporáneos de la civilística en Alemania y en otros países. 
Pero antes es oportuno precisar en qué acepción se emplea aquí la palabra "sistema", porque este vocablo es usado en diferentes sentidos. ${ }^{22}$

En términos genéricos y relativamente vagos, suele llamarse sistema a un conjunto de elementos de cualquier orden relacionados entre sí y armónicamente conjugados. Pero, a los efectos del presente estudio, se debe hacer a un lado esa acepción de la voz "sistema".

A veces se identifica sistema con organismo. Pero tampoco nos importa esta acepción, por varias razones. En primer lugar, cuál sea el concepto de organismo es un punto muy controvertido, sobre todo, porque de organismo se habla en muy diferentes y heterogéneas zonas del ser: en el mundo de lo biológico, animal y vegetal; metafóricamente, en el campo de las realidades sociales; y también en el plano de los complejos unitarios de ideas. En ninguna de esas acepciones, organismo viene en cuestión para el tema aquí planteado. Por otra parte, algunos pensadores, como Ferrater Mora, sostienen que el concepto de lo sistemático es más amplio que el de lo orgánico.

Asimismo se emplea la noción de "sistema" como equivalente a un método o a un tipo prácticamente útil de ordenación de un conjunto de materiales. Por ejemplo: de los papeles en una oficina; de las instituciones jurídicas que pertenecen a una determinada rama del Derecho, verbigracia al Derecho civil —éste es el único sentido aceptable en la ciencia jurídica dogmático-técnica-; o de los libros que componen una biblioteca.

En sentido filosófico algo más rigoroso, suele llamarse "sistema" la ordenación de una variada multiplicidad en un todo unitario y bien estructurado, dentro del cual cada elemento singular se encuentra en relación con el todo y con las otras partes, y dentro del cual ocupa su lugar adecuado. Este es el sentido que a la palabra sistema da O. Ritschl. En realidad, esta conceptuación de "sistema" rigoriza un poco más el sentido meramente empírico de "ordenación".

La acepción de la palabra "sistema" que importa destacar aquí, pues es a ella a la que se refiere la imposibilidad de llevarla a cabo en el terreno de la jurisprudencia es la siguiente. Tenemos un sistema, cuando partiendo de un juicio apodíctico, partiendo de una verdad irrefutable, incondicionada y necesaria, se deducen conclusiones, inmediatamente de ese punto de partida, o mediatamente de juicios cuyo conocimiento deriva de la primera verdad apodíctica. Esta acepción la encontramos ya en Aristóteles, quien contrapone el pensamiento sistemático al pensamiento dialéctico, el cual, este último, deriva de argumentaciones que tienen alguna fuerza de convicción.

20 Cfr. David Hilbert, Grundlagen der Geometrie, 4. Auflage, 1913; Hilbert-Ackermann, Grundzüge der theoretischen Logik, 3. Auflage, 1949; Rudolf Carnap, Abriss der Logistik, 1929; O. Ritschl, System und systematische Methode, 1906; Francesco Orestano, Prolegomeni alla Scienza del Bene e del Male, 1934; Ulrich Klug, Juristische Logik, 2. Auflage, 1958. 
Nicolai Hartmann ${ }^{23}$ describe el sistema en los siguientes términos: "el modo de pensar sistemático parte de la totalidad. Aquí la concepción es lo primero y sigue siendo lo dominante de modo decisivo. Aqui no se pone en cuestión el punto de vista. Por el contrario, el principio básico es aceptado ante todo, desde un comienzo, necesariamente. Y, partiendo de ese principio, de ese punto de vista, base del sistema, son seleccionados los problemas. Aquellos problemas que no resulten compatibles con el punto de vista básico de ese sistema son rechazados. Se los considera como cuestiones mal planteadas. No es que se prejuzgue o se predetermine nada sobre la solución de los problemas mismos; pero, en cambio, sí, sobre los límites dentro de los cuales puede moverse la solución."

Pues bien, en los últimos 15 años Viehweg ${ }^{24}$ y Perelman ${ }^{25}$ han mostrado que, con la excepción de dos siglos - desde mediados del xviII y hasta apenas de mediados del $\mathrm{xx}$ - el pensamiento jurídico y la práctica de la jurisprudencia a lo largo de toda su historia $y$, sobre todo, en sus etapas más gloriosas, nunca fueron "sistemáticos", ni intentaron serlo. Por el contrario, fue pensamiento de tipo aporético, problemático, deliberador, argumentativo. El pensamiento aporético procede de modo inverso al sistemático. El pensamiento aporético, problemático, argumentativo, puede contar sólo con conocimientos fragmentarios; $\mathrm{y}$, al abordar un problema, puede seleccionar a voluntad un número mayor o menor de puntos de vista, que parezcan ser de algún peso, o dotados de alguna fuerza de convicción. A esos puntos de vista, generalmente aceptados por la influencia de una autoridad tradicionalmente reconocida, los antiguos griegos y romanos los llamaban tópicos. La función de los tópicos consiste en servir para la consideración de los problemas, para iluminar todas las varias facetas de éstos, para contemplar todas sus vertientes, para ponderar el alcance y el valor de cada una de las diversas soluciones posibles.

La característica argumentativa de ese tipo de pensamiento lo contrapone al pensamiento de tipo matemático, de espíritu cartesiano, que busca sobre todo y por encima de todo la evidencia, y que desdeña cualquier

23 Cfr. Nicolai Hartmann, "Diesseits von Idealismus und Realismus", en Kant-Studien, XXIX, 1924.

$24 \mathrm{Cfr}$. Theodor Viehweg, Topih und Jurisprudenz: ein Beitrag zur rechtswissenschaftlichen Forschung, 3. durchgesehene Auflage, Beck, München, $196_{5}$.

25 Cfr. Chaim Perelman, Logique Formelle, Logique Juridique, Université de Bruxelles, 1959; Rhétorique et Philosophie, Presses Universitaires de France, Paris, 1952; y Olbrechts L. Tytega, Traité de l'Argumentation, Bruylant, Bruxelles, $195^{8}$. Véase también: Stephen Edelston Toulmin, The Uses of Argument, Cambridge University Press, 1964; Brian Barry, Political Argument, Routledge \& Kegan Paul, London-New York, 1965; Julius Stone, Legal System and Lawyers' Reasonings, Stanford University Press, 1964: R. A. Wasserstrom, The Judicial Decision: Towards a Theory of Legal Justification, 1961; Juan David Garcia Bacca, Planes de Lógica Juridica, Caracas, 1958; M. Ramaswamy, The Creative Role of the Supreme Court, 1957 . 
proposición que no posea ese carácter de lo obvio, de lo indiscutible, de lo exacto, de lo preciso.

Ahora bien, los mencionados autores $y$ otros han mostrado que hay un enorme volumen de pensamiento, sobre todo el que atañe a los problemas prácticos del comportamiento humano, y muy especialmente del social, que no pueden de ninguna manera ser incluidos dentro de los límites angostos de la evidencia y del razonamiento de índole matemática y exacta. En ese enorme volumen de pensamiento no matematizante, que abarca variadas especies de razonamientos prácticos, se emplea la deliberación, lo plausible, lo probable, lo prudente, lo justo, lo eficaz, etc., en cuanto que él está inevitablemente fuera de la certidumbre exacta de la matemática. Es el pensamiento que Aristóteles llamó "dialéctico", en el sentido de que él se va produciendo a través de un diálogo, de una deliberación, de una contraposición entre argumentos, todo lo cual es muy diferente de la evidencia y de la demostración racionalista.

Los más grandes juristas, lo mismo jueces que legisladores, frente a una cuestión debatida, emplearon ese tipo de pensamiento: analizar el problema en cada uno de sus lados, componentes, implicaciones axiológicas, efectos prácticos, significaciones en vista de determinados propósitos, orientación hacia ciertas metas.

Fue sólo después de mediados del siglo xvıI, cuando algunos juristas, bajo la influencia y el prestigio que habia cobrado el pensamiento de tipo cartesiano, matematizante, concibieron el incorrecto propósito de sistematizar la doctrina del Derecho positivo y la jurisprudencia. Leibniz alentó la ambición de matematizar el pensamiento jurídico y de sistematizar la ciencia del Derecho. A tal finalidad dedicó muchos esfuerzos; pero, al fin y a la postre, confesó su fracaso: la imposibilidad de esa empresa, entre otras razones, por la multivocidad o equivocidad del idioma $y$, también, por la irrupción imprevisible de nuevos hechos que inevitablemente quiebran las líneas del proyectado sistema.

Aristóteles y Cicerón propugnaron para el tratamiento de los problemas jurídicos el método de la tópica, dialéctica y retórica: la vía del análisis de los problemas particulares, de la deliberación y de la ponderación comparativa de los diversos argumentos esgrimidos por las partes en conflicto. Eso mismo fue lo que hicieron los más grandes jurisconsultos romanos. E igual tradición perduró en las obras de los glosadores y comentaristas en los siglos XIII y xIv (Accursio, Bartolo, Baldo, Gribaldo, Mopha, etc.). Eso es lo que se vino haciendo a través de todo el Medioevo y lo que continuó poniéndose en práctica durante el Renacimiento.

Después, desde mediados del siglo xviıI y a lo largo del xIx, cobró ímpetu la manía de la sistematización. Pero tal propósito desembocó siempre en un estrepitoso fracaso. 
Las reflexiones criticas, producidas en el presente, han mostrado de modo irrebatible la imposibilidad de convertir la ciencia jurídica y la jurisprudencia en logística. La realización de este propósito tropieza con insuperables obstáculos. Sería necesario encontrar una o varias proposiciones que, en última instancia, resultasen apropiadas para funcionar como el punto de partida axiomático del cual pudiesen deducirse todas las demás proposiciones, procediendo así en forma de una especie de cadena. Pero la realización de tal propósito no ha tenido éxito en ninguna de las muchísimas veces en que ha sido intentado.

Por otra parte, adviértase que las conclusiones o derivaciones llevarían inevitablemente consigo la posibilidad de diferentes y variables interpretaciones.

Añádase a todo eso otro punto: la multiplicidad variada de áreas jurídicas, las cuales no pueden ser unificadas en un solo cuerpo, impide la elaboración de un sistema en el sentido lógico de esta palabra.

Por fin, y esto es lo más importante, el obstáculo mayor es la irrupción de nuevos hechos, insospechados, imprevistos, que suscitan la necesidad de nuevas interpretaciones de añejas normas, o que provocan la elaboración de nuevas normas. Tanto lo uno como lo otro vendrian a romper irremediablemente las supuestas líneas lógicas del sistema.

Claro que todo lo dicho no impide ni prohíbe que los juristas procedan a ordenar sus materiales, mediante conceptos clasificatorios de normas e instituciones. Es más, necesitan hacerlo así, pues de lo contrario se moverían en un mar de confusiones, en un totum revolutum, casi en un caos. Pero tales ordenaciones clasificatorias, meramente empíricas, no constituyen propiamente un sistema. Y si se le quisiera denominar así, sistema, entonces esta palabra tendría tan sólo la primera de las acepciones que mencioné al comienzo del desarrollo de este epígrafe: el sentido de una simple organización práctica de los materiales con los que se trabaja.

La estructura total de la jurisprudencia puede ser determinada tan sólo partiendo de los problemas. Las partes componentes de la jurisprudencia, sus conceptos y proposiciones deben permanecer ligados de modo especial a los problemas. Así lo reconocen, entre muchos otros, los civilistas alemanes de vanguardia: Fritz von Hippel, ${ }^{26}$ Joseph Esser ${ }^{27}$ y Walter Wilburg. ${ }^{28}$

20 Cfr. Fritz von Hippel, Zur Gesetzmässigkeit juristischer Systembildung, 1930.

27 Cfr. Joseph Esser, "Elementi di Diritto Naturale nel Pensiero Dogmatico", en Nuova Rivista di Diritto Comparato, Diritto Sociale, e Diritto dell'Economia, 1952.

28 Cfr. Walter Wilburg, Entwicklung eines beweglichen Systems im bürgerlichen Recht, $195^{\circ}$. 
10. No hay conceptos esenciales de instituciones juridicas históricas

Ya expliqué antes que no hay conceptos esenciales de las instituciones jurídicas históricas, tales como el arrendamiento, la servidumbre de paso, el fideicomiso, el recurso de casación, etc. Pero lo que importa subrayar ahora es otro mayúsculo error cometido como consecuencia de haber supuesto equivocadamente que era posible encontrar nociones esenciales de meros productos históricos. Este error fue elevar arbitrariamente a supuestos conceptos esenciales las nociones que eran meramente descriptivas de unas normaciones históricas contingentes, y haber hecho funcionar tales nociones empíricas como premisas mayores de los mal imaginados silogismos de la decisión jurisdiccional.

Aquel frenesí de un exorbitado deductivismo, que antes relaté y critiqué, no se limitó a tomar como premisa mayor de un silogismo una norma legal, sino también un imaginario concepto esencial de una institución.

¡Cuántos desvaríos teóricos se produjeron y cuántas injusticias prácticas se perpetraron en nombre de la supuesta sacrosanta esencia de la hipoteca, o del arrendamiento, o del cuasicontrato!

\section{Las normas juridicas individualizadas son auténticas normas juridicas}

Otro de los errores mayúsculos -estrechamente conectado con todos los demás a los que he aludido- fue el de suponer que el orden jurídico-positivo estaba constituido sólo por las normas generales (constitución, leyes y reglamentos), y que las decisiones jurisdiccionales eran simplemente aplicación del Derecho.

Las críticas contra ese error empezaron a producirse desde hace ya casi $5^{0}$ años, desde diferentes puntos de vista y por los cauces de muy diversas escuelas. Primero, la crítica de Kelsen y, casi de modo simultáneo, pero independiente, una serie de análisis de varios juristas franceses y anglosajones (Morin, ${ }^{29}$ Cardozo, ${ }^{30}$ etc.). Y, después, un diluvio de sucesivas críticas cada vez más demoledoras.

Las normas individualizadas de las decisiones jurisdiccionales son tan "Derecho" como las normas generales, porque, al igual que éstas, aquéllas forman parte del orden jurídico total. $\mathrm{Y}$ tales normas individualizadas no constituyen una mera deducción lógico-formal de la norma genérica, sino que aportan algo no contenido en ésta, a saber: las calificaciones y determinaciones individuales, que no están ni pueden estar especificadas en la regla general. Si no fuese así, entonces no sería necesaria la intervención de un órgano jurisdiccional que declarase lo que se deba hacer en un caso concreto, y basta-

29 Cfr. op. cit.

30 Cfr. obras citadas. 
ría con que un agente ejecutivo de la autoridad procediera a la imposición del cumplimiento, o de la sanción (civil o penal).

Pero yo me he atrevido a dar todavía un paso más, hacia adelante, y a sostener que no basta con decir que las normas individualizadas son tan Derecho como las normas generales. Entiendo que debemos darnos cuenta de que son más Derecho que las normas generales, sencillamente porque son las únicas normas jurídicas perfectas, es decir, completas, cosa que las normas generales no pueden ni podrán ser nunca. En efecto, ninguna norma general constituye una norma completa, es decir, susceptible de ser cumplida directamente o impuesta de un modo ejecutivo a las situaciones concretas de la vida, que esa norma general trató de regir. La ley habla con las únicas palabras con que puede hacerlo, con palabras generales y abstractas. En cambio, todas las situaciones de la vida son singulares y concretas. Para que una norma general pueda ser cumplida o impuesta, es necesario tejer un puente entre la generalidad de ella y la particularidad del caso concreto.

La norma general suministra las directrices para que ella sea individualizada en cada caso concreto, bien por el sujeto llamado a cumplirla o por su abogado consejero, bien, en caso de conflicto, por el órgano jurisdiccional. Sólo la norma individualizada es susceptible de ser cumplida o de ser impuesta de un modo inexorable.

\section{No hay diferencia entre creación y aplicación del Derecho}

Otra versión, en apariencia diferente, del mismo error que acabo de examinar bajo el epígrafe precedente, consiste en haber establecido una diferencia entre "creación" y "aplicación" del Derecho.

La crítica producida contra la equivocación de negar el carácter de auténtico Derecho a las normas individualizadas vale por entero contra ese otro dislate de diferenciar entre creación y aplicación del Derecho.

Por una parte, Kelsen ${ }^{31}$ —desde su ángulo formalista-, y, por otra parte, desde el punto de vista de las realidades, otros muchos iusfilósofos y juristas prácticos (Cardozo, ${ }^{32}$ Gray, ${ }^{33}$ Frank, ${ }^{34}$ Husson,, ${ }^{35}$ Marty, ${ }^{36}$ etc.) han demostrado que esa tesis es insostenible. El proceso de creación del Derecho comienza con el acto constituyente y prosigue, sin solución de continuidad, a través de la legislación, de la emisión de reglamentos, de la celebración de negocios

31 Cfr. obras citadas.

32 Cfr. obras citadas.

33 J. C. Gray, Nature and Sources of the Law, 2nd. ed., 1921.

34 Cfr. obras citadas.

35 Cfr. Léon Husson, Les Transformations de la Responsabilité: Étude sur la Pensée Juridique, Presses Universitaires de France, Paris, 1947.

30 Cfr. Gabriel Marty et Pierre Raynaud, Droit Civil: Introduction Générale à l'Étude du Droit, et des Institutions Judiciaires, Les Personnes, Sirey, Paris, 1961. 
juridicos, hásta la decisión jurisdiccional (judicial o administrativa). Ese proceso es un proceso continuo hacia una particularización cada vez mayor que, por fin, desemboca en la individualización por el acto jurisdiccional decisorio.

\section{Critica de la separación entre cuestión de hechos y cuestión de Derecho}

Tradicionalmente, durante todo el siglo xix y una parte del $\mathrm{xx}$ se enseñó que en el proceso jurisdiccional hay que separar la llamada "cuestión de hecho" y la "cuestión de Derecho", sobre todo bajo la influencia de la doctrina jurídica francesa. Pero esa tajante diferenciación ha entrado en crisis desde hace más de treinta años.

Entre otros, Llewellyn ${ }^{37}$ mostró con diáfana claridad, y de manera irrebatible, que la consideración de los hechos implicados en un proceso se presenta siempre entrelazada con la norma relativa a tales hechos.

Omitiré la mención de otras muchas observaciones en sentido parejo a las producidas por ese representante del movimiento jurídico realista norteamericano. Pero, en cámbio, quiero ilamar enfáticamente la atención hacia el acontecimiento de que haya sido precisamente un ilustre iusfilosofo francés, León Husson, ${ }^{38}$ quien rompiendo con la recia e inerte tradición de su pais, haya atacado de un modo más decisivo esa supuesta diferencia total entre la cuestión de hecho y la cuestión de Derecho. Dice Husson que en muchas sentencias, si las analizamos bien, se percibe que el meollo de las mismas, el fallo o la decisión, entrelaza de modo inseparable los hechos calificados y las normas. En todo caso, la interpretación de un texto y la interpretación de los hechos no son ni pueden ser independientes: el texto es interpretado en vista de su proyección a los hechos; así como los hechos son analizados en vista de su relación con los textos normativos. ${ }^{39}$

Me doy perfecta cuenta de que esta doctrina hace temblar los cimientos sobre los cuales Francia, y otros países que la imitaron, construyeron el recurso de casación, respecto del cual se supone que no puede entrar en absoluto en el análisis de la cuestión de hecho, y debe limitarse exclusivamente al problema de la correcta interpretación de las pertinentes normas jurídicas (sustantivas y procesales). Por eso, tal crítica contra la diferencia tajante entre la cuestión de hecho y el problema de Derecho tropezará con una enérgica oposición de quienes se sienten arrastrados por tradiciones inertes, las cuales en realidad hoy son ya caducas. Pero más tarde o más temprano, se recono-

37 Cfr. obras citadas.

ss Cfr. op. cit.

39 Cfr. también: Travaux du Centre National de Recherches de Logique, Le Fait et le Droit, Etudes de Logique Juridique, Bruylant, Bruxelles, 1961 ; Etudes de Logique Juridique, dos volúmenes, publiés sous la direction de Ch. Perelman, Bruylant, Bruxelles, 1961 et. 1966 . 
cerá que hay razones decisivas para eliminar aquella diferencia estricta entre la cuestión de hecho y la cuestión de Derecho. Hoy en día, empiezan a reconocerlo así, incluso grandes iusfilósofos franceses, como, por ejemplo, Gabriel Marty.

\section{Creación del Derecho desde abajo hacia arriba}

Según señalé ya en el desarrollo del epígrafe número 9 del presente trabajo, durante las fases más gloriosas del desarrollo del Derecho, por ejemplo, en la obra de los pretores romanos y en la acción de los jueces anglosajones, la producción del Derecho se efectuó partiendo de los problemas planteados por las realidades sociales, esto es, desde abajo hacia arriba. Y, hoy en día, se vuelve a abogar enérgica y persuasivamente en favor de tal procedimiento.

Pero en los siglos xviI, xux, e incluso en el $\mathrm{xx}$, por un prejuicio de exacerbado racionalismo - sobre todo en los paises latinos-, se concibió el ideal de elaborar el Derecho positivo partiendo de unos supuestos axiomas y por via deductiva de pretensiones pseudosistemáticas. Esto trajo consigo no pocos casos de flagrante y funesto desacuerdo entre lo ordenado por las normas y las realidades sociales efectivas. Unas veces: la total inoperancia de la ley; otras veces, estragos, fricciones, malestar, e incluso cosas peores, por el choque entre una norma utópica y la realidad alejadísima de ella.

A mi entender con acierto, dice Emil Brunner que es indebido y funesto querer construir el orden juridico desde arriba hacia abajo, por una vía deductiva. Es indebida esta orientación, que algunos Estados adoptaron desde el siglo xviII, en mayor o menor medida, influidos por una tendencia de puro racionalismo de tipo matemático. $\mathrm{Y}$ es monstruoso lo que de manera exacerbada hace el Estado totalitario, que se cree omnipotente, ignora los derechos básicos de la persona humana y de las comunidades, e impone por medio de la fuerza bruta un orden inspirado en una fantasmagórica ideología.

Frente a la equivocación cometida por los Estados que se inspiraron en esquemas racionalistas, muchas veces utópicos, y frente a la monstruosidad criminal de los Estados totalitarios, hay que propugnar la comunidad popular y la organización estatal construida desde abajo hacia arriba, es decir de modo federalista. Todas las ordenaciones o instituciones se dan por razón de los seres humanos; y nunca los seres humanos se dan por razón de las instituciones. Por eso se tiene que empezar con el hombre individual, dotado de dignidad personal, el único ser que tiene auténtica conciencia. Pero, puesto que el individuo está abocado a la comunidad, a las comunidades, ante todo debe tomarse en cuenta la realidad y la misión de la familia, la cual es la comunidad originaria y precede incomparablemente en derechos a toda otra sociedad, incluso al Estado. Ahora bien, la familia no es la única comunidad que precede al Estado en cuanto a derechos. Entre la familia y el Estado 
existe una serie de comunidades intermedias, todas ellas con fundamental precedencia sobre el Estado, a saber: todas aquellas formas de sociedad que pertenecen necesariamente a la humana existencia. También el Estado pertenece necesariamente a la vida humana, pero sólo en tanto en cuanto y en la medida en que forzosamente tiene que haber una unión superior, superlativamente comprensiva, que abarque todas las formas primarias de sociedad, y en la medida en que sobre el Estado, como instituto del monopolio de la coerción, recae todo aquello que el hombre no hace voluntariamente, sino tan sólo forzado. Pero antes de que el Estado haya sido organizado, existe asimismo una serie de comunidades económicas de trabajo, de comunidades culturales, etc. Todo eso es pre-estatal. El Estado es sólo el último eslabón de esa cadena de mancomunidades.

No es el Estado quien pone en movimiento esas manifestaciones de la vida. No es tampoco el Estado quien tiene que inventar abstractamente las reglas según las cuales aquellas manifestaciones deben desenvolverse. Ni es tampoco el Estado quien pueda decir lo que sea justo o injusto en este campo. Todo esto radica en la naturaleza de las cosas, en la índole de esas relaciones y del hombre que vive en ellas. Al Estado le corresponde actuar como protector, como custodio, como vigilante, como reguiadur, peró de ninguna manera como creador, ni como factor constitutivo de tales realidades. El Estado debe hacer únicamente aquello que tan sólo él puede hacer por virtud de estas dos dimensiones: por virtud de ser el grupo de ámbito más comprensivo, y por virtud de ser la forma de organización dotada de impositividad coercitiva.

Luis Recaséns Siches

INSTITUTO DE INVESTIGACIONES FILOSÓFIGAS

Universidad Nagional Autónoma de México 